\title{
Effectiveness and safety of ITCA 650 vs currently available injectable GLP-1 RAs in type 2 diabetes: a phase IIIb, pragmatic RCT
}

\author{
J. New1, M. Gibson², V. Lehner-Martin ${ }^{3}$, N. Branscombe ${ }^{4}$, M. Garcia ${ }^{5}$, F. Vitry ${ }^{6}$
}

1. Salford Royal NHS Trust, Diabetes, Salford, United Kingdom. 2. North West E Health, Manchester, United Kingdom. 3. Servier Affaires Médicales, Suresnes, France. 4. Servier International, Suresnes, France. 5. Servier Research and Development, Slough, United Kingdom. 6. Servier International Research Institute, Suresnes, France.

\section{BACKGROUND}

Non-adherence to type 2 diabetes (T2D) medications contributes significantly to poor glycemic control, and results in increased morbidity, mortality, and healthcare costs.

- ITCA 650 (figure 1), a subdermally placed osmotic mini-pump delivering continuous subcutaneous exenatide for up to 6 months, does not require any action by the patient to ensure medication adherence, maximizing the potential to realize the full therapeutic efficacy of exenatide.

- A real-world setting is the ideal environment to capture any potential clinical benefits associated with ITCA 650 over the long term.

\section{OBJECTIVES}

The primary objective of this study is to demonstrate the benefit on long-term effectiveness of ITCA 650 compared with injectable GLP-1 receptor agonists (RAs), given as add-on to oral therapy in patients with T2D inadequately controlled with two existing oral hypoglycaemic agents.

- Secondary and other objectives are:

- To evaluate the effect of ITCA 650 compared with injectable GLP-1 RA on glycated haemoglobin (HbA1C), body weight, and on modification of background anti-diabetic treatment

- To assess safety and tolerability of ITCA 650 vs injectable GLP-1 RAs,

- To evaluate the adherence and persistence of study treatment,

- To characterize treatment satisfaction,

- To assess healthcare resource utilization.

\begin{tabular}{|c|c|}
\hline Main Inclusion Criteria & Main Exclusion Criteria \\
\hline $\begin{array}{l}\text { 1. Male or female patients, aged } \geq 18 \text { years, with T2D } \\
\text { 2. Body mass index } \geq 30 \mathrm{~kg} / \mathrm{m}^{2}\left(\geq 27.5 \mathrm{~kg} / \mathrm{m}^{2} \text { for Asian and }\right. \\
\text { Black patients) and } \leq 45 \mathrm{~kg} / \mathrm{m}^{2}\end{array}$ & $\begin{array}{l}\text { 1. Contraindications to the injectable GLP-1 RA planned for the } \\
\text { patient if randomized to the GLP- } 1 \text { RA arm } \\
\text { 2. On regimen of } \geq 3 \text { oral anti-diabetic treatments }\end{array}$ \\
\hline $\begin{array}{l}\text { 3. On stable regimen of two oral anti-diabetic treatments, } \\
\text { both at stable daily doses for } \geq 3 \text { months prior to selection } \\
\text { (patients under DPP-4 inhibitor will be switched to ITCA } 650 \\
\text { or iniectable GLP-1 RA at inclusion) }\end{array}$ & $\begin{array}{l}\text { 3. Previous treatment with any GLP-1 RA } \\
\text { 4. Current treatment with insulin } \\
\text { 5. Estimated GFR }<45 \mathrm{~mL} / \mathrm{min} \text {. or according to the GLP-1 RA }\end{array}$ \\
\hline $\begin{array}{l}\text { 4. Inadequately controlled with HbA1c } \geq 7.5 \%(58 \mathrm{mmol} / \mathrm{mol}) \\
\text { and } \leq 12 \%(108 \mathrm{mmol} / \mathrm{mol})\end{array}$ & $\begin{array}{l}\text { summary of product characteristics (SmPC) for a more } \\
\text { restrictive background treatment } \\
\text { 6. History of acute or chronic pancreatitis } \\
\text { 7. Severe gastrointestinal disease including gastroparesis } \\
\text { 8. History of medullary thyroid cancer or multiple endocrine } \\
\text { neoplasia type } 2 \text { or thyroid nodule not fully evaluated }\end{array}$ \\
\hline
\end{tabular}

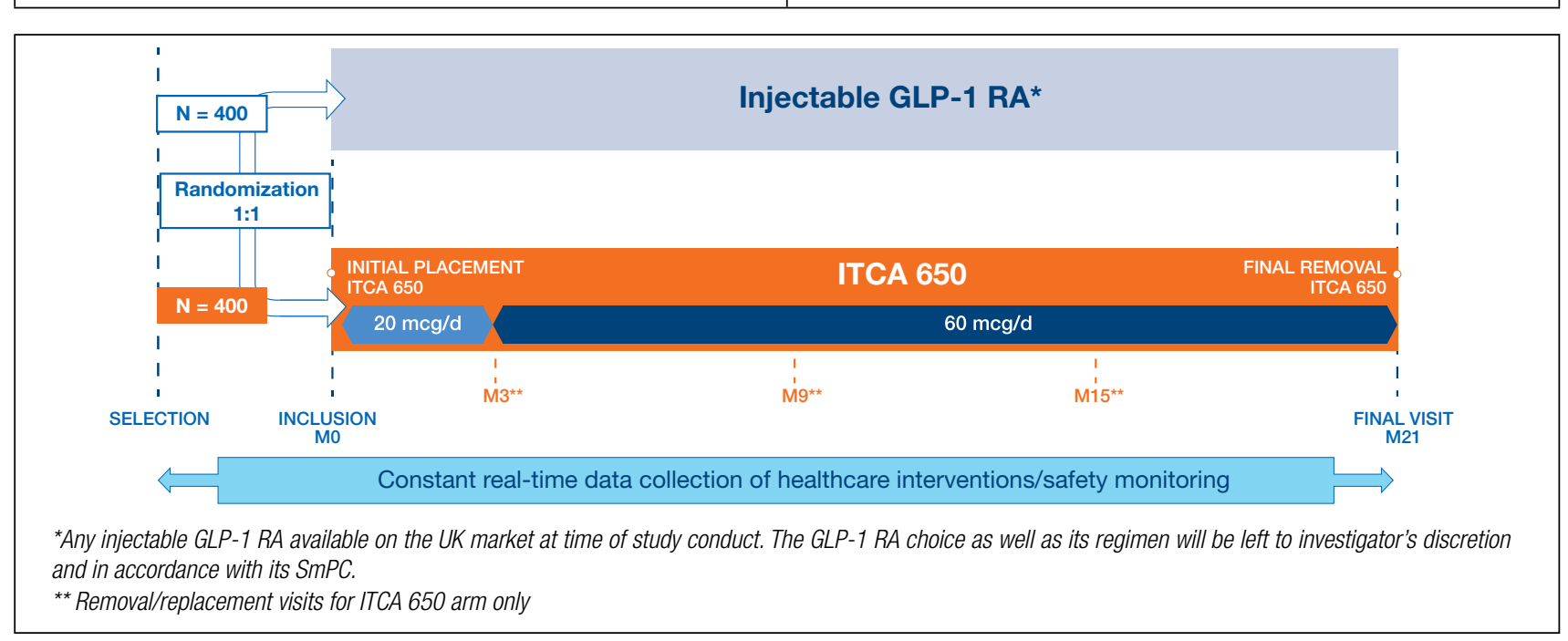

Figure 2: Study Design.

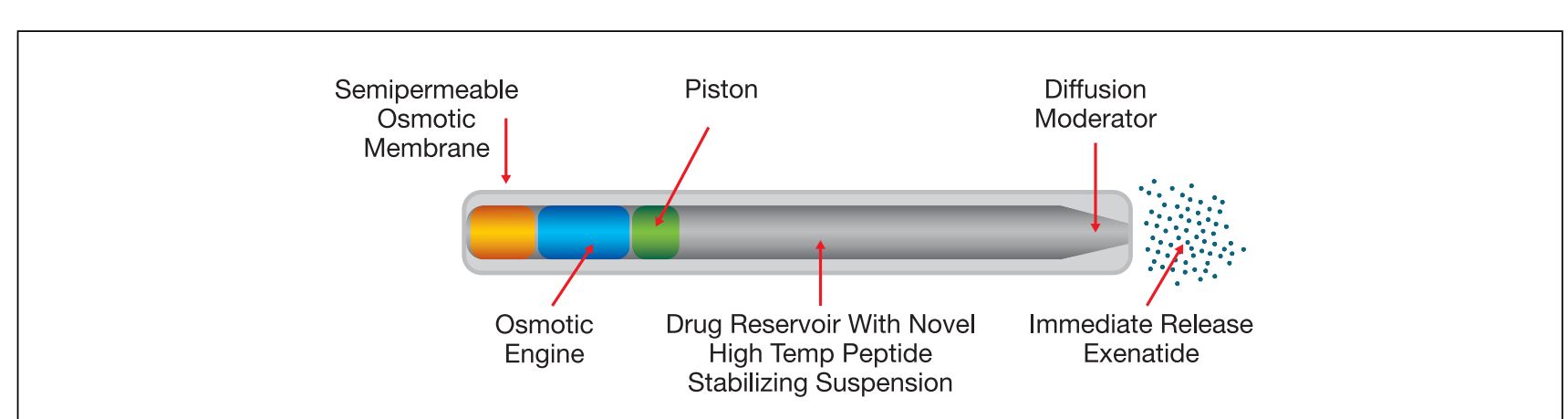

Figure 1: The ITCA 650 osmotic mini-pump.

\section{METHODOLOGY}

This pragmatic Randomized Controlled Trial (pRCT) in adult patients with T2D will evaluate the clinical effectiveness and safety of ITCA 650 vs physicians' choice of injectable GLP-1 RAs currently available in the UK (figure 2).

- This study will utilize linked data systems developed by North West E-Health (NWEH, Manchester, UK) that connect multiple National Health Services information sources and facilitates near to real-time collection and remote monitoring of safety data (figure 3).

- 3 common visits will be planned: selection, M0, M21

- 3 additional visits for patients randomized to the ITCA 650 arm: M3, M9, M15 visits with healthcare practitioner for removal/replacement of the device.

For both arms, the frequency of any further visits related to the management of T2D will be left to the investigator's judgement i.e. will not be imposed.

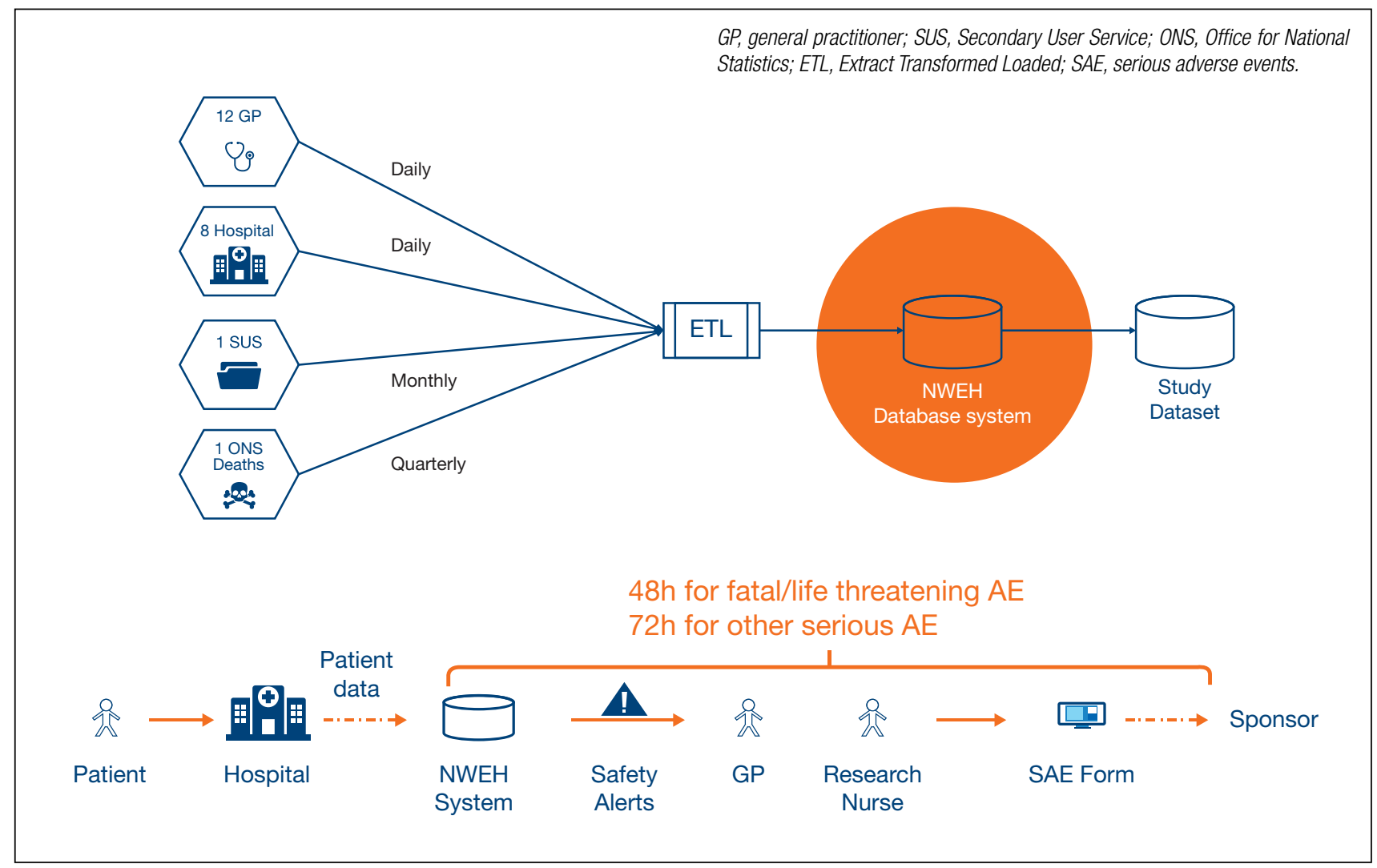

Figure 3: Data feed sources in the NWEH database system.

High quality safety reporting processes will be achieved by the remote monitoring of patient's electronic healthcare records using NWEH's unique ConneXon trial delivery platform. This novel new method of safety monitoring allows safety events to be reported close to real-time.

\section{ENDPOINTS}

\begin{tabular}{|c|c|c|}
\hline Primary Endpoint & Effectiveness Endpoints & Safety Endpoints \\
\hline $\begin{array}{l}\text { Composite variable that defines achievers as patients who } \\
\text { satisfy both criteria: } \\
\text { 1. HDA1C }<53 \mathrm{mmol} / \mathrm{mol}(<7.0 \%) 0 \mathrm{R} \text { reduction from baseline in } \\
\text { HDA1C } \geq 11 \mathrm{mmol} / \mathrm{mol}(\geq 1 \%) \text { at } 21 \text { months; AND } \\
\text { 2. No modification* of anti-diabetic treatment over } 21 \text { months } \\
\text { *Switch to a new drug class, discontinuation of study treatment } \\
\text { (ITCA650 or injectable GLP-1 RA), add-on of a new drug class, } \\
\text { dose increase of the background oral treatment compared to } \\
\text { baseline dose (exclude GLP-1 RA dose adjustment required } \\
\text { by the therapeutic scheme and short-term (<14 day) use of } \\
\text { insulin if associated with hospitalization/medical procedure) }\end{array}$ & $\begin{array}{l}\text { HbA1C (main secondary endpoint: change in HbA1c from baseline to M21) } \\
\text { Body weight } \\
\text { - Modification of anti-diabetic treatment } \\
\text { - Adherence/Persistence } \\
\text { - Patient Reported Outcomes (Diabetes Treatment Satisfaction Questionnaire [status and change], patient opinion on study } \\
\text { treatment convenience) } \\
\text { - Healthcare resource utilization (eg, days in hospital, physician contacts, concomitant treatment costs, total direct medical } \\
\text { costs, etc) will be collected such that the "all cost", "treatment-related cost" and "diabetes-related cost" profiles can be } \\
\text { understood over time } \\
\text { - Vital signs }\end{array}$ & $\begin{array}{l}\text { - Adverse events related to the study drug or to a procedure required } \\
\text { by the study protocol } \\
\text { - Serious adverse events } \\
\text { - Adverse events of special interest* } \\
\text { *Hypoglycemia, gastrointestinal events, events related to the } \\
\text { administration site, device procedure events, cardiovascular (CV) } \\
\text { events (CV death, non-fatal myocardial infarction, non-fatal stroke, } \\
\text { congestive heart failure, hospitalization for unstable angina), all- } \\
\text { cause mortality, acute pancreatitis, pancreatic cancer, thyroid cancer, } \\
\text { hypersensitivity to the study drug, acute renal failure } \\
\text { - Adverse events leading to study treatment discontinuation }\end{array}$ \\
\hline
\end{tabular}

\section{DISCUSSION}

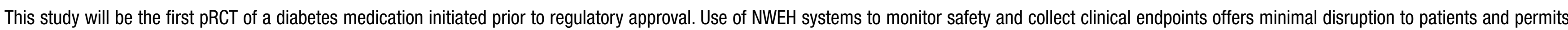

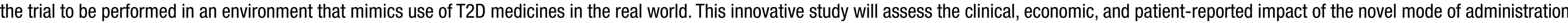
of ITCA 650 in patients with T2D as compared with injectable GLP-1 RAs. 